\title{
ФБРАЗОВАТЕЛЬНАЯ СРЕДА
}

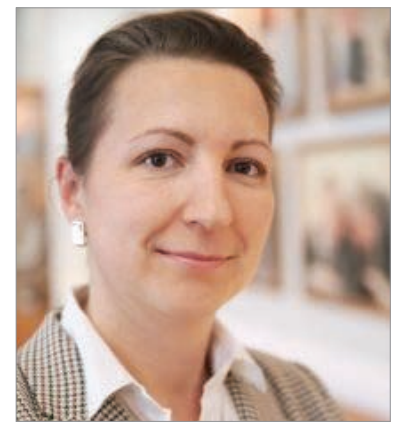

Мария Сергеевна ЦAPEBA,

кандидат философрских наук, дочент,

доцент кафредры юридического перевода, директор Института юридического перевода

Университета имени

О.Е. Кутафина (МГЮА) mahen_koln@hotmail.com 125993, Россия, г. Москва, ул. Садовая-Кудринская, д. 9

\section{Дополнительное образование в области иностранных языков}

\begin{abstract}
Аннотация. Являясь структурным подразделением Университета имени О.Е. Кутафрина (МГЮА), Институт юридического перевода реализует уникальные программы языкового образования, предоставляя своим выпускникам возможность стать частью элитного международного сообщества юристов. Индивидуальные образовательные траектории, в основе которых лежат индивидуальные потребности потенциальных слушателей, позволяют выбрать максимально комфортную языковую программу по юридическому английскому, фрраниузскому, немецкому, испанскому и китайскому языкам.

Поддержание качества и своевременная актуализация программ под растущие потребности современного общества входят в приоритетные задачи Института как подразделения ведущего юридического вуза страны. Внедрение новых образовательных технологий и моделей преподавания, диверсификация и переориентирование программ в сторону практического применения и коммуникации отвечают современным тенденциям развития образования. Подготовка высококвалифицированных специалистов в области профрессионального иностранного языка юриспруденции повышает конкурентоспособность и востребованность выпускников как в профрессиональной среде юристов, но и в смежных профрессиях — таких, как переводчик или преподаватель.
\end{abstract}

Ключевые слова: институт юридического перевода МГЮА, иностранные языки МГЮА, дополнительное языковое образование, переводчик в сфрере профрессиональной коммуникации.

DOI: $10.17803 / 2311-5998.2021 .86 .10 .110-116$

M. S. TSAREVA, Cand. Sci. (Philosophy), Associate Professor, Associate Professor of the Faculty of Legal Translation, Head of the Department of Legal Translation of the Kutafin Moscow State Law University (MSAL) mahen_koln@hotmail.com 9, ul. Sadovaya-Kudrinskaya, Moscow, Russia, 125993

\section{Supplementary Foreign Language Education}

Abstract. As a structural subdivision of the Kutafin Moscow State Law University (MSAL), the Department of Legal Translation implements a number of unique language education programs, providing its graduates with the opportunity to become a part of the elite international community of lawyers. Language education is based on the individual needs of potential students 


\begin{tabular}{|c|c|}
\hline 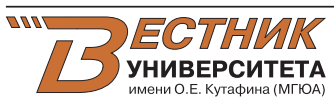 & $\begin{array}{l}\text { Царева М. С. } \\
\text { Дополнительное образование } \\
\text { в области иностранных яЗыкОв }\end{array}$ \\
\hline
\end{tabular}

and allows you to choose the most comfortable language program in legal English, French, German, Spanish and Chinese.

Maintaining the quality and timely updating of programs to meet the growing needs of modern society are among the priority tasks of the Institute, as a subdivision of the country's leading law university. The introduction of new educational technologies and teaching models, diversification and reorientation of programs towards practical application and communication meets modern trends in the development of education. The training of highly qualified specialists in the field of a professional foreign language of jurisprudence increases the competitiveness and demand for graduates both in their professional environment - lawyers, and in related professions - such as a translator or teacher.

Keywords: Department of Legal Translation, Kutafin Moscow State Law University (MSAL), foreign languages, additional language education, translator in the field of professional communication.

$\mathrm{Y}$ ниверситет имени О.Е. Кутафина (МГЮА) является лидером юридического образования, и к преподаванию иностранных языков здесь традиционно относятся с особым вниманием. Постоянно развиваясь и совершенствуясь, МГЮА постепенно поставил языковое образование на уровень намного выше обычной программы юридического вуза, предоставляя своим студентам уникальные возможности осваивать дополнительные специализированные программы, совершенствовать свои навыки английского, немецкого или французского на привилегированных условиях, покорять новые горизонты и становиться конкурентоспособными и востребованными специалистами не только в профессиональной среде юристов, но и в смежных профессиях — таких, как переводчик или преподаватель.

Сейчас в структуре Университета работает Институт юридического перевода, который занимается подготовкой и реализацией дополнительных программ по иностранным языкам, в его состав входит кафедра юридического перевода. Сто́ит заметить, что в настоящее время на рынке образовательных услуг наблюдается значительный рост интереса целевой аудитории к программам иностранного языка. Этим обусловлены и рост конкуренции в данном секторе, и высокие запросы со стороны потребителей. В приоритетные задачи Института всегда входили обеспечение качества преподавания, постоянная актуализация образовательных программ. Миссия института юридического перевода заключается в подготовке высококвалифицированных специалистов в области профессионального иностранного языка юриспруденции.

Спектр языков и программ Института довольно широк. Слушатели изучают английский, немецкий, французский, испанский и даже китайский язык. Перечень программ может удовлетворить любые запросы аудитории, ведутся активный процесс диверсификации программ Института, внедрение новых образовательных технологий и моделей преподавания.

Подробнее сто́ит остановиться на образовательных программах, которые были созданы или переработаны за последнее время. При создании программ и для 
того, чтобы избежать путаницы и помочь потенциальным слушателям выбрать именно то, что им подходит, Институт пошел по пути индивидуальных образовательных траекторий. Их три - «Переводчик», «Юрист» и Наука». В основе лежат глубокие знания общего иностранного языка, которые можно получить по программе «Основы юридического иностранного языка». Она также модульная, и каждый стартует на том уровне, на котором он находится. Это может быть как английский, так и (или) французский, немецкий, испанский, китайский язык.

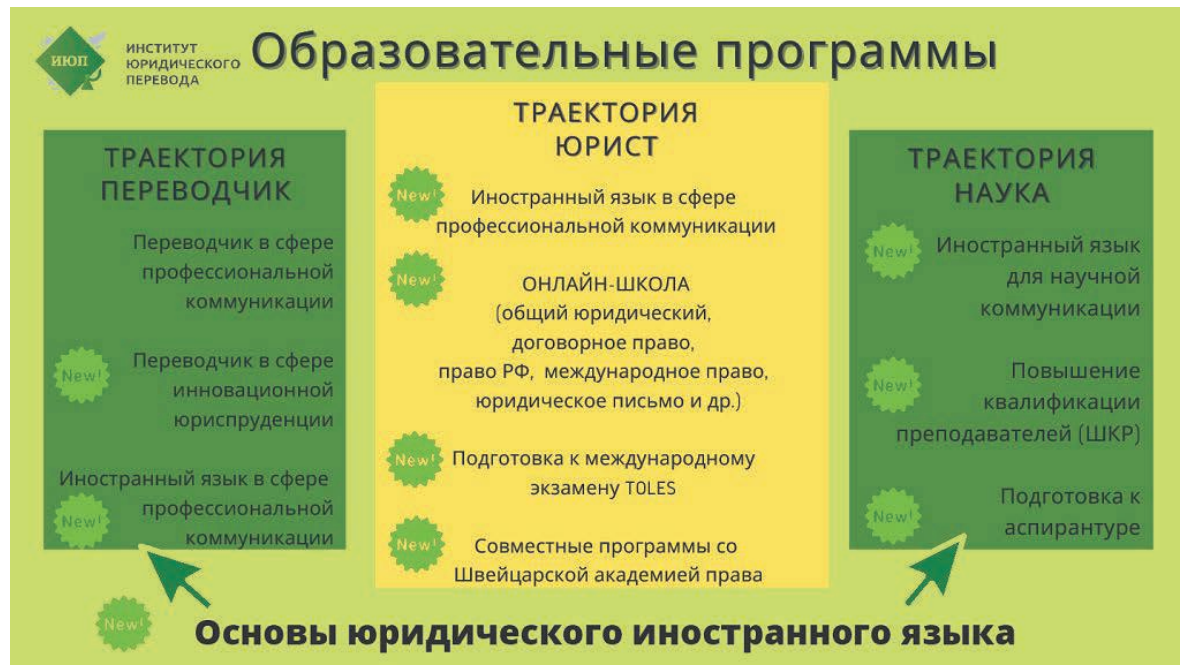

Программой, с которой началось дополнительное языковое образование в МГЮА и которая до сих пор занимает лидирующее место, является программа «Переводчик в сфере профессиональной коммуникации», рассчитанная на четыре года, которую подавляющее большинство студентов МГЮА осваивают параллельно с основной, каждый в своем институте. Данная программа предлагается и для внешних слушателей.

Программа «Переводчик в сфрере профессиональной коммуникации» реализуется в МГЮА с 2002 г. За это время многое изменилось как в подходах к образованию, так в требованиях к содержанию и результатам. За последний год данная программа получила свою новую жизнь, была коренным образом обновлена, наполнена новыми дисциплинами, новым содержанием и новыми методическими подходами. Она стала более практико-ориентированной, нацеленной на бо́льшую самостоятельную работу студентов.

В перечень дисциплин программы были введены проектная работа и институт тьютерства как руководство проектной работой слушателей. То есть в каждом семестре слушатели теперь получают разного рода задания - будь то разработка проекта, составление презентации (в формате печа-куча) и т.д., которые курируются преподавателем в течение отдельных аудиторных групповых занятий (4-6 часов в семестр в зависимости от сложности задания).

Основная задача данной дисциплины — изложить и прокомментировать российское законодательство и судебную практику на иностранном языке. Работа 


\begin{tabular}{|c|c|}
\hline 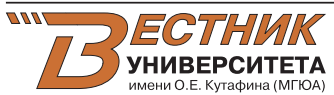 & $\begin{array}{l}\text { Царева М. С. } \\
\text { Дополнительное образование } \\
\text { в области иностранных языков }\end{array}$ \\
\hline
\end{tabular}

над проектами ведется как самостоятельно, так и в группах и ориентирована на практику и овладение новыми методами работы с информацией: уметь ее находить, консолидировать, анализировать и презентовать. Эти навыки пригодятся в будущей профессиональной жизни, научат работать в коллективе, группе. Это частично разгружает слушателей от аудиторной работы и предоставляет больший простор для совершенствования самостоятельной работы.

Также был видоизменен формат промежуточной аттестации, а со следующего года такое изменение затронет и итоговую аттестацию. Промежуточная аттестация проводится теперь в форме круглых столов и коллоквиумов, с четко разработанным фондом оценочных средств. Это позволяет вводить в практику полученные на занятиях знания, умения и навыки и не ограничиваться вытягиванием билетов, пересказом «топиков» и ответом на вопросы, не забывая о том, что все это помогает развивать у слушателей так называемые soft skills.

Следующим аспектом развития программы «Переводчик» стала ее модульность, а именно разделение ее на несколько коротких, но самодостаточных программ, которые тем не менее могли бы собираться в единое целое. Данный план имеет долгосрочную перспективу и предусматривает несколько этапов. Сегодня программа «Переводчик» уже разбита на два больших блока, добавлен подготовительный этап и таким образом выстроено ступенчатое изучение иностранных языков в зависимости от стартового уровня подготовки:

- основы юридического иностранного языка (для начинающих);

- иностранный язык в сфрере профессиональной коммуникации (для продолжающих) (первый модуль программы «Переводчик»);

- переводчик в сфере профессиональной коммуникации (для продолжающих). Обучение по данной траектории складывается, таким образом, из трех ступеней, по окончании каждой из которых можно получить документ об освоении программы.

Не такой популярной, но от этого не менее важной мы считаем программу «Английский для научной коммуникации». Это уже EAP — English for Academic Purposes. Bce больше зарубежных университетов предлагают продолжить образование в другой стране: можно пойти в магистратуру, поехать на стажировку. Данная программа предлагается в первую очередь магистрам, аспирантам и всем, кто занимается наукой и хочет понимать лекции, делать конспекты, реферировать текст, делать презентации, правильно использовать стили, эффективно читать научную литературу.

В этом году прошел набор в новое структурное подразделение Университета - Высшую школу права, в стратегические задачи которой входит подготовка специалистов, обладающих высшим уровнем компетенций, среди которых, без всяких сомнений, находится владение профессиональным иностранным языком. Для студентов ВШП была разработана специальная программа — «Переводчик в сфере инновационной юриспруденции», которая была с успехом запущена.

Готовят в Институте и к международным экзаменам. В настоящее время Институт юридического перевода является центром подготовки и площадкой для сдачи международного экзамена по юридическому английскому - TOLES (test of legal english skills). 
Отдельно выделяется работа со студентами по сетевым программам (Швейцарская академия права, Тулуза и др.). Предусматривается подготовка как на начальном этапе - перед поездкой, так и в течение обучения, когда студенты возвращаются на территорию России. Предполагаются занятия по английскому и фрранцузскому языкам. Институт юридического перевода выбран Швейцарской академией международного права в качестве площадки для языковой подготовки своих студентов.

В планы Института на ближайшее будущее входит ввод следующего блока программ.

Предполагается открытие курса «Юридическое письмо» для высокого уровня владения иностранным языком. В качестве преподавателей здесь планируется привлекать юристов, носителей иностранного языка. Программа предлагается не только на английском, но и на французском и немецком языках.

Следующий блок - разработка и внедрение программ для магистров. Как показывает опыт, у них нет возможности идти на большие программы из-за нехватки времени и своих вечерних занятий. Поэтому предлагается давать им отдельные специальные модули как общего характера, так и узкой направленности по наиболее востребованным темам, таким как «интеллектуальная собственность», «международное право», «договорное право». Это будет удобно сделать, так как эти программы уже существуют в качестве элективных курсов в программе «Переводчик» и могут с небольшой коррекцией быть предложены в качестве отдельных программ.

Также невысокий уровень подготовки магистров требует отдельного курса по общему английскому языку, в качестве которого могут выступать уже упомянутые выше «Основы юридического иностранного языка».

Большинство из вышеперечисленных программ может быть предложено иностранным студентам МГЮА, так как обучение идет на иностранном языке по коммуникативным методикам. Такие планы скоро будут реализованы.

В разговоре о языковом образовании сегодня невозможно пройти мимо темы дистанта. Следует отметить, что во время пандемии коронавируса преподаватели успешно адаптировались к новым условиям обучения, освоив различные форматы удаленного взаимодействия. Опыт работы в период пандемии показал, что онлайн-занятия не менее эффрективны, чем занятия в аудиториях, если применять надлежащую методику. Конечно, многие предпочитают непосредственное общение, но продуктивную атмосферу можно создать и в Zoom.

Благодаря вынужденному уходу в дистанционный фрормат мы поняли, что данное направление также необходимо развивать, и открыли онлайн-школу изучения иностранных языков, поступить в которую могут все желающие. Это значительно расширяет аудиторию, позволяя преподавать юридический иностранный язык тем, у кого нет возможности приехать в Москву. Занятия проходят 2 раза в неделю 


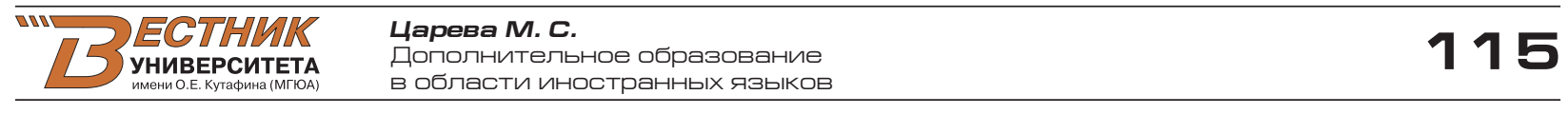

по два академических часа (90 минут) на протяжении 12 недель в вечернее время. По окончании слушатели получают удостоверение о повышении квалификации установленного образца. Предусмотрены следующие модули подготовки:

- общий юридический язык (foundation, higher или advanced);

- договорное право;

- право интеллектуальной собственности;

- международное право и др.

Если слушатели осваивают четыре модуля программы и успешно проходят итоговую аттестацию, они получают диплом МГЮА о профессиональной переподготовке. Модули при этом можно проходить в любом порядке.

Важным шагом в развитии Института юридического перевода представляется интеграция с другими структурными подразделениями, как общей направленности, так и занимающихся дополнительным образованием: это привлечение совместно с Управлением международного сотрудничества иностранных преподавателей к программам Института, иностранных студентов, студентов сетевых программ, а также помощь при подготовке перед поездкой на стажировки в рамках программ по обмену.

Это совместные проекты с Центром довузовской подготовки -

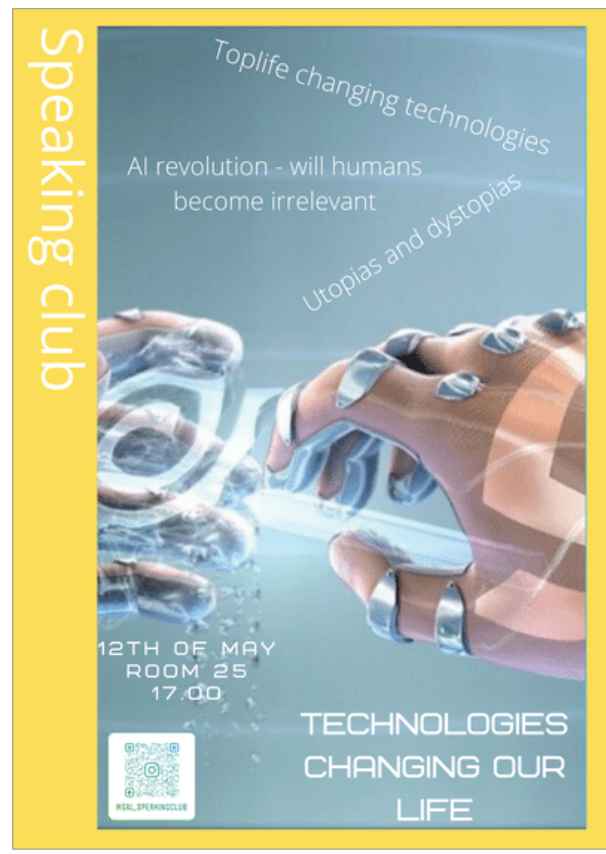
при разработке программ для подготовки к ЕГЭ по английскому языку, к вступительному испытанию по языку для поступления в аспирантуру, включение языковых модулей в программы Института повышения квалификации, взаимодействие с кафедрой правового моделирования.

Преподаватели кафедры юридического перевода размышляют сейчас над разработкой своей интерактивной образовательной платформы.

Также Институт организует и проводит межвузовскую Олимпиаду по юридическому английскому языку, которая в этом году приняла более 200 участников из разных университетов России и ближнего зарубежья.

В 2021 г. совместно с ассоциацией студентов был запущен проект «Разговорный клуб», куда приходят ребята просто поболтать на английском на заранее заданную тему, к которой они готовятся, решая задания от лидеров клуба в социальных сетях. Лидеры клуба каждый раз разные, и у членов клуба есть возможность поближе познакомиться с преподавателями кафедры юридического перевода. Было проведено пять таких встреч, проект продолжит свою работу и в следующем году. Все это создает определенную языковую среду, где свое место есть как для слушателей Института, так и для тех, кто только собирается ими стать.

В планы Института на следующий год входит реализация нового проекта «Лаборатория перевода». Ее три основных направления: мастер-классы юристов-практиков в вопросах юридического перевода, мастер-классы переводчиков, которые будут освещать актуальные проблемы и тренды в переводе, и своеобразное «бюро переводов», где участники проекта будут работать с потенциальными работодателями, наставниками. Это будет большой серьезный проект, реализуемый совместно с кафедрой практической юриспруденции.

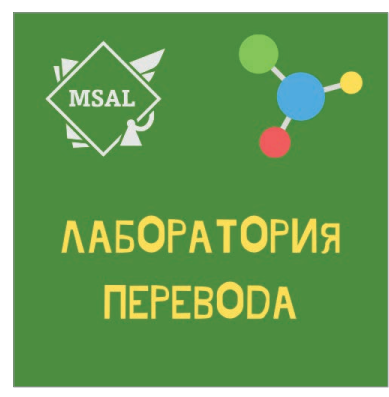


Также предусматривается возобновление научного кружка по юридическому английскому языку для студентов и развитие другой воспитательной и просветительской деятельности для приобщения слушателей Института к межкультурной коммуникации и развитию общекультурных компетенций.

\section{БИБЛИОГРАФИЯ}

1. Бердамбетова А. Организация обучения иностранным языкам в вузе // Молодой ученый. - 2019. — № 50 (288). - С. 323-324.

2. Будникова А. С. Реализация и применение аспектов методики обучения иностранному языку по индивидуальной образовательной траектории // Ученые записки. Электронный научный журнал Курского государственного университета — 2019. — № 4 (52). — C. 177-180. — URL: http://scientific-notes.ru/\#newnumber?id=153.

3. Калиновская В. В. Юридическая терминология: заимствование и перевод // Вестник Университета имени О.Е. Кутафина (МГЮА). — 2017. — № 11. C. $68-73$.

4. Пикалова В. В. Учебное пособие по английскому языку в сфрере права интеллектуальной собственности как средство повышения уровня профрессиональной коммуникативной компетенции юристов-переводчиков // Вестник Университета имени О.Е. Кутафина (МГЮА). — 2017. — № 11. — С. 106-112. 